\title{
DEL COMPORTAMIENTO Y EL FENÓMENO: EL A PRIORI DE CORRELACIÓN
}

\section{ON BEHAVIOUR AND PHENOMENON: THE A PRIORI CORRELATION}

\author{
Alejandro Escudero PÉREZ* \\ Departamento de Filosofía. UNED
}

RESUMEN: ¿Es cierto que gracias a una propiedad llamada «intencionalidad» yo salgo de mí mismo y consigo alcanzar todo aquello que está fuera de mí? ¿No estará, más bien, la comprensión ordinaria sostenida y atravesada por una correlación a priori entre un cuerpo y una situación, un comportamiento y un fenómeno? :No estaré yo —en tanto existir fáctico- originariamente «fuera de mí» en el Afuera del mundo? Este artículo aborda éstas y otras cuestiones semejantes.

PALABRAS CLAVE: intencionalidad, comportamiento, cuerpo, fenómeno, situación, ser-en-el-mundo.

ABSTRACT: Is it true that I can go out of myself and I may attain what is beyond me by means a property called «intentionality»? The ordinary understanding not will it be rather sustained and crossed by a priori correlation between a body and a situation, behaviour, and a phenomenon? Could it be that I — as a factual being — am outside myself originally in the outside world? This article discusses these and other similar issues.

KEYWORDS: Intentionality, behaviour, body, phenomenon, situation, being-in-the world.

* Artículo realizado con los fondos del Proyecto de Investigación FFI2009-11921, denominado «Interpretación y verdad en la hermenéutica fenomenológica». 


\section{Introducción}

En 1925, en el curso del semestre de verano celebrado en la Universidad de Marburgo, Martin Heidegger explicaba —a nuestro juicio con razón-que uno de los hallazgos principales de la fenomenología de Husserl se cifraba en el «fenómeno» puesto de relieve a partir de la noción de «intencionalidad» ${ }^{1}$. Esta afirmación, entendemos, puede y debe ampliarse: reparando en él nos plantamos ante uno de los (re)descubrimientos más decisivos de la filosofía del siglo XX. ¿Por qué sería irresponsable y censurable perderlo de vista? Mencionaremos a continuación algunas de las razones con las que avalar la tesis enunciada.

Gracias a la «intencionalidad» — al «fenómeno» al que apunta este términose puede conseguir, en primer lugar, desterrar el embrollo profundo por el que nos precipitamos cuando entendemos la «experiencia» o la "comprensión» —en su más ordinario acaecer- a partir de la separación de un «sujeto» y un «objeto». Esta crucial virtualidad suya ha sido destacada con nitidez por una serie de autores a los que haremos caso en el conjunto de nuestro planteamiento:

— «Si el referirse-a, que es lo que quiere decir la expresión «intencionalidad", se entiende correctamente, entonces no puede ser tomado como un carácter del representar, un representar que, por su parte, quedaría dentro de lo psíquico, como podría parecer de acuerdo con Brentano. De otro modo, caemos en la situación problemática de admitir una esfera del alma dentro de la cual aparecen representaciones que se dirigen intencionalmente a imágenes que también pertenecen a lo psíquico. En ese caso, nos encontramos, igual que Brentano, ante al problema: ¿cómo se relaciona la esfera psíquica respecto de la esfera física? Sin embargo, la intencionalidad de un percibir no se dirige a una imagen en el alma, que habría que poner todavía en relación con lo ente, sino a lo ente mismo. Sólo si establecemos este sentido primario de la intencionalidad tenemos la base necesaria para un punto de partida apropiado al asunto. Se objeta que entonces desaparecería el problema de la relación de sujeto-obje-

\footnotetext{
${ }^{1}$ M. Heidegger, Prolegómenos para una historia del concepto de tiempo, ed. Alianza, 2006. Al asunto de la «intencionalidad» se refiere el $\$ 5$, pp. 46-70.
} 
to. Ciertamente, pero esto es justamente la finalidad del concepto de intencionalidad: dejar de lado este pseudoproblema» ${ }^{2}$.

— «... la idea de intencionalidad nos permite ir más allá del problema de la relación sujeto-objeto» ${ }^{3}$.

— «Este es el significado profundo de la idea de intencionalidad: superación de la contradicción sujeto-objeto ... [así] la fenomenología se presenta como [posible] superación del enfrentamiento sujeto-objeto, idealismo-realismo» ${ }^{4}$.

${ }^{2}$ M. Heidegger, Principios metafísicos de la lógica, ed. Síntesis, 2009, p. 157. En 1927 decía Heidegger — complementando lo que se acaba de exponer- : «... la intencionalidad no es ni algo objetivo, subsistente como un objeto, ni es subjetiva en el sentido de algo que ocurre dentro de un supuesto sujeto, cuyo modo de ser queda totalmente indeterminado. La intencionalidad no es ni objetiva ni subjetiva en el sentido usual, aunque es ciertamente ambas cosas, pero en un sentido mucho más originario, ya que la intencionalidad, que pertenece al existir (Dasein), hace posible que este ente, existiendo, se comporte respecto a lo ente. Con la exposición adecuada de la intencionalidad se vuelven discutibles los conceptos de sujeto y subjetividad, no sólo lo que entiende la psicología por sujeto, sino también lo que ésta misma debe presuponer tácitamente, en tanto que ciencia positiva, sobre la idea y la constitución del sujeto, y lo que la filosofía misma ha definido hasta ahora ontológicamente de una forma imperfectísima y ha dejado en la oscuridad. También está insuficientemente definido el concepto filosófico tradicional de sujeto con relación a la constitución básica de la intencionalidad... Que hoy, bajo la influencia de la fenomenología, se hable tanto sobre la intencionalidad, o se introduzca para ello otra palabra, no muestra que el fenómeno así denominado se haya visto fenomenológicamente», Los problemas fundamentales de la fenomenología, ed. Trotta, 2000, p. 95.

3 Emmanuel Levinas, La teoría fenomenológica de la intuición, ed. Sígueme, 2004, p. 70 (véanse también, por ejemplo, las páginas 77 y 82, en las que se insiste en esto mismo). Miguel GarcíaBaró, en su artículo, "Introducción a un tratado de filosofía primera", afirmaba rotundamente: "La teoría acerca de la intencionalidad de la conciencia es el nudo central de todos los problemas de la filosofía” (Revista de Filosofía, n. ${ }^{\circ}$ 6, 1991, p. 247); ahora bien jes cierta la tesis — tan extendidade que la «intencionalidad» es de la conciencia? El conjunto de este ensayo pretende ser - lo logre o no es otra cuestión - una refutación de esta idea.

4 Ricardo Sánchez Ortiz de Urbina, La fenomenología de la verdad: Husserl, ed. Pentalfa, 1986, pg. 49. En la medida en que Husserl, a partir de 1907, embarcó a la fenomenología en la senda del «idealismo» puede decirse de él lo que señala, en los siguientes textos, Paul Ricoeur: «Lo que la hermenéutica cuestiona en primer lugar del idealismo husserliano es que haya inscrito el descubrimiento inmenso e insuperable de la intencionalidad en una conceptualización que reduce su alcance, la relación sujeto-objeto», Del texto a la acción, ed. FCE, 2001, p. 44; «... a pesar de haber nacido con el descubrimiento del carácter universal de la intencionalidad, la fenomenología no ha seguido el consejo de su propio hallazgo, es decir que la 'conciencia' tiene su sentido fuera de sí misma. La teoría idealista de la constitución del sentido en la conciencia ha lleva a sí a la hipóstasis de la subjetividad ... la fenomenología corre siempre el riesgo de quedar reducida a un subjetivismo transcendental. El modo radical de poner término a esta confusión que reaparece una y otra vez es desplazar el eje ... del problema de la subjetividad al del mundo», Ibíd., p. 52.

ENDOXA: Series Filosóficas, n. ${ }^{\circ}$ 25, 2010, pp. 235-266. UNED, Madrid 
El último fragmento aducido nos pone sobre la siguiente pista: a través de la recta explicitación de la «intencionalidad» se pueden dar algunos pasos relevantes que ayuden a poner fuera de juego la presunta alternativa entre el «realismo» (desarrollado bajo la creencia en una absoluta primacía del «objeto») y el «idealismo» (alentado por la opinión de que lo primordial es el «sujeto»). Desarticular ambas posiciones — asentadas, por cierto, en supuestos comunes- constituye un reto complicado; pero, ¿por qué es necesario conseguirlo? Heidegger expone así el meollo de la cuestión:

— «... precisamente el tan discutido problema de la relación sujeto-objeto con todas sus modalidades, es un signo de que no se ha ido más allá del viejo planteamiento de la antigüedad y de que el problema central sigue sin abordarse... Se pueden inventar siempre nuevas teorías para solucionar el problema sujeto-objeto. Pero estos inventos tienen el dudoso mérito de que aumentan la confusión y no hacen sino suministrar nuevas pruebas de que manifiestamente se sigue sin abordar el problema decisivo»"

- «Cuando se evoca la relación sujeto-objeto y especialmente cuando se hace para caracterizar la subjetividad, entonces hay que decir que con esta relación sujeto-objeto y con su referencia a ella se deja fuera algo esencial y se pierde de vista lo decisivo. Lo que se deja fuera es la característica de esta «relación entre», que es precisamente lo que habría que aclarar. Se pierde de vista el concepto genuino de subjetividad, en la medida en que se pasa por alto que la «relación a» pertenece precisamente a la esencia de la subjetividad. Por supuesto que con la tesis: a la esencia de la subjetividad le pertenece la relación con posibles objetos, todavía no está todo claro ... y esto precisamente en razón de la aparente obvia inteligibilidad de comenzar con una relación sujeto-objeto. Es sorprendente que el problema que esta tesis enuncia no se haya movido de su sitio... Aquí se encuentra justamente la dificultad, pues dando por descontadamente claro el punto de partida se consideran como igualmente obvias las premisas de la solución y sus condiciones. La teoría del conocimiento de la segunda mitad del

\footnotetext{
5 M. Heidegger, Introducción a la filosofía, ed. Cátedra, 1999, pp. 72-73. El caso de Heidegger — del llamado "primer Heidegger»— es muy interesante porque muestra que una cosa es ver con lucidez que ni el realismo ni el idealismo son posiciones filosóficamente consistentes y otra muy distinta es conseguir ofrecer una alternativa solvente a las mismas, pues muy a pesar suyo Ser y tiempo desemboca en un peculiar idealismo.
} 
siglo XIX y de los últimos decenios ha puesto siempre en la base de los planteamientos de sus cuestiones la relación sujeto-objeto, pero tanto los intentos idealistas como los realistas de explicación tenían que fracasar porque no estaba determinado suficientemente lo que había que explicar. Cómo la explicación precedente del 'fenómeno' que hay que esclarecer determina por completo toda la problemática se muestra en que, precisamente en nuestro problema, el alcance de la primera aclaración llega hasta un punto, que es el que tiene que ser alcanzado y realizado, donde se esfuma un posible problema, en el sentido de la teoría del conocimiento realista e idealista ... el problema de la relación de sujeto-objeto debe ser planteado de un modo totalmente nuevo y, por supuesto, dejando a un lado los intentos llevados a cabo hasta ahora ${ }^{6}$.

De cara a afrontar todas estas cuestiones en absoluto basta pregonar algo así como la «intencionalidad»: lo principal estriba en esclarecerla atinadamente de tal manera que manteniéndose firmes en ella se destierren embrollos y enredos que impiden entender el común y corriente acaecer de la comprensión, de la ordinaria experiencia ${ }^{7}$. Ahora bien, una apropiada clarificación de la «intencionalidad» es mucho más difícil de lo que parece: el camino está plagado de obstáculos, lleno de trampas. Por su ubicación sistemática el principal peligro —aunque no el único- consiste en sucumbir a la tentación sea de «objetivar» la «intencionalidad» sea de «subjetivarla», de nuevo es Heidegger quien nos pone sobre aviso:

«Inicialmente rechazamos dos tergiversaciones naturales y persistentes de la intencionalidad. Resumimos brevemente ambas interpretaciones falaces. Primero ha de decirse contra la errónea objetivación de la intencionalidad que ésta no es una relación subsistente entre dos entes subsistentes, sujeto y objeto, sino una estructura que constituye el carácter de relación del comportarse del existir (Dasein) como tal. Segundo, en oposición a la errónea subjetivación de la intencionalidad hay que señalar que la estructura intencional de los comportamientos no es algo inmanente a lo que se llama sujeto» ${ }^{8}$.

${ }^{6}$ M. Heidegger, Principios metafisicos de la lógica, op. cit., pp. 152-155.

7 Malentendiéndose, por cierto, la propia comprensión, la misma experiencia, tarde o temprano se ofusca, atasca, constriñe, desvía, desorienta.

${ }^{8}$ M. Heidegger, Los problemas fundamentales de la fenomenología, op. cit., p. 94. 
Empezaremos llevando a cabo una exposición del peculiar «fenómeno» de la «intencionalidad» por nuestra cuenta y riesgo, intentado que sea él mismo el que guíe y conduzca los resultados de la indagación. Precisamente por esto desde el primer momento se nos impone un preciso "cambio de vocabulario" — cambio que encierra algo mucho más profundo que el recurso a tal o a cual término-: en vez de «intencionalidad» acudiremos a la expresión «a priori de correlación»; Husserl ya la empleaba — por ejemplo en el $₫ 48$ de La crisis de las ciencias europeas y la fenomenología transcendental - pero vamos a intentar ganar para ella un significado en buena medida distinto al que tiene en su obra.

Una vez realizada esta exposición —y en base a ella- entablaremos una breve discusión con Husserl y con Heidegger; a pesar de que ambos son una constante y magnífica fuente de inspiración filosófica en honor a la verdad nos parece necesario afirmar que malograron su propio hallazgo porque lo situaron en las coordenadas del idealismo moderno (un marco éste que gracias a la puesta de relieve del «a priori de correlación» está abocado a transformarse). Tanto en Husserl como en Heidegger encontramos, con distintos matices, una concepción «extática» de la intencionalidad que, nos parece, distorsiona gravemente el «fenómeno» originario al que apuntamos con la expresión «a priori de correlación».

Dos observaciones antes de comenzar. La filosofía, especialmente en su punto de partida, es un peculiar recuento de «obviedades», incluso de "trivialidades»; cuando explicitemos el «a priori de correlación» —y precisamente porque es un «fenómeno primario»— será preceptivo acudir a «obvias trivialidades» que son importantes ante todo porque pasan inadvertidas 9 . Eso obvio y trivial nos resul-

\footnotetext{
9 Con gran perspicacia, y adentrándose en el tema que nos ocupa, Heidegger decía sobre ello: «Se podría creer que estas son trivialidades sin igual que debería avergonzarnos proclamar. Con todo no nos neguemos a fijar expresamente esta tesis: los comportamientos se comportan respecto de algo, se dirigen hacia un qué; o, en términos formales, se relacionan con él. Mas ¿qué podemos hacer con la tesis de la relación de los comportamientos con aquello respecto de lo que se comportan? ¿Es esto ya filosofía? Dejemos indeciso si es o no filosofía. Admitamos incluso que no es, o que todavía no es, filosofía. Tampoco nos importa qué estamos haciendo con la afirmación de estas supuestas trivialidades, si con ella penetramos o no en los misterios del mundo y del existir (Dasein). Únicamente nos importa una cosa: que no se nos escurra entre las manos esta tesis trivial y lo que se menciona con ella, que nos acerquemos algo más a ella. Entonces es posible que esta supuesta trivialidad se torne un enigma. Quizá esta verdad de Perogrullo se convierta en uno de los más excitantes problemas para el que sabe filosofar. Es decir, para el que ha aprendido a entender que lo evidente de suyo es el auténtico y el único tema de la filosofía», Los problemas fundamentales de la fenomenología, op. cit., pp. 86-87.
} 
ta tan cercano y consabido que por un lado resulta difícil de explicitar y, por otro, fácil de tergiversar (las desfiguraciones de los «fenómenos básicos» a los que se dirige la filosofía acechan constantemente y ninguna investigación puede creerse enteramente libre de incurrir en alguna de ellas). Por último diremos que nuestro ensayo es meramente preliminar; rozaremos muchos temas y tocaremos muchos problemas que reclaman una investigación minuciosa, detallada — nos proponemos, eso sí, al menos, situarlos y localizarlos según su sistematicidad propia.

\section{La comprensión y su correlación a priori}

Con el fin de cumplir su primera tarea la filosofía arranca en medio de una «epojé». Ésta consiste, por un lado, en abstenerse de pronunciar juicios esenciales, existenciales o sobre nexos causales, por otro lado, en suspender la «actitud ordinaria» en la que olvida — con un motivo inicialmente legítimo- que la experiencia, el saber, la comprensión, está regida por una compleja maraña de «condiciones de posibilidad». La filosofía — recordando eso ordinariamente olvidado- emprende así, en primera instancia, la ardua tarea de explicitar y sacar a la luz — gracias a una paciente y detallada «descripción analítica»— las condiciones de posibilidad de la comprensión ${ }^{10}$. La «dimensión» de las condiciones de posibilidad es tan compleja como difícil de desentrañar: aquí sólo intentaremos recorrer un pequeño trecho suyo. En sus primeros pasos la exposición está obligada a ser muy «estilizada»: enfocará sólo piezas sencillas y, por lo tanto, evitará deslizarse por los complicados vericuetos con los que se topará en cada tramo.

Lo primero es siempre el común y corriente acaecer de la comprensión, un acaecer constante, incesante. Toca ahora preguntar - ya desde la epojé filosófica-: considerado en su mínima expresión ¿̇en qué consiste ese ordinario acaecer de la comprensión? Precisamente en el continuo «encuentro» entre un comportamiento y un fenómeno: entre «alguien» que comprende y «algo» comprendido. Desde luego ambos, así nombrados, no son sino una enorme y fantástica «abstracción». ¿¿De qué? Ya lo veremos más adelante. Pero de entrada

${ }^{10}$ Las condiciones de posibilidad de la comprensión óntica — del saber fenoménico (la ciencia, el arte, etc.) — residen y se asientan en la comprensión del ser, es decir: comprendiendo «ser» (su acontecer) son comprendidas las condiciones de posibilidad rectoras de la comprensión común y corriente. Es por esto por lo que el saber filosófico merece llamarse «ontológico».

ENDOXA: Series Filosóficas, n. ${ }^{\circ}$ 25, 2010, pp. 235-266. UNED, Madrid 
hay secuencias de comportamientos y un orden múltiple de fenómenos diferenciados. Sin embargo -operando como decimos una enorme "estilización», una profunda «abstracción»— nos referimos por el momento, necesariamente, a un comportamiento comprensor y a un fenómeno comprendido. Nos mantendremos firmes aquí hasta que sea menester pasar a otro nivel de análisis. Llega el siempre delicado capítulo de los ejemplos: es menester acudir a ellos, a pesar de que a veces puedan confundir más que aclarar. ¿Un comportamiento y un fenómeno? Por ejemplo: un astrofísico aprieta el disparador de la cámara con la que el telescopio fotografía una lejana galaxia; el cocinero, con un preciso movimiento, da la vuelta en la sartén a una tortilla; el apasionado abrazo de la amada a su enamorado; el pintor traza en el lienzo una suave curva con un pincel bien empastado; el alcalde, en acto solemne, firma y pregona un bando municipal; el creyente, arrodillado, reza a su dios representado en el altar por una estatua; el alumno, en la pizarra, resuelve una ecuación de segundo grado; el cartero introduce una carta en un buzón ... Sea cual sea la calidad y el poder esclarecedor de estos ejemplos la pregunta filosófica oportuna es la siguiente: ¿̨cuál es la más cercana "condición de posibilidad» del encuentro ordinario entre un comportamiento y un fenómeno? Eso que hemos llamado «a priori de correlación». Antes de ahondar en él resulta conveniente acentuar lo siguiente: gracias a que el a priori de correlación rige de antemano en el común y corriente acaecer de la comprensión caben una serie de «casos» que cuando se los toma por lo primordial conducen a la teoría a precipitarse por una pendiente en la que el asunto originario resulta desfigurado o deformado. Algunos de esos «casos» — necesitados de un estudio detallado y exhaustivo- son: un fenómeno «antecede» a un comportamiento o le «sucede» (y viceversa); un fenómeno "falta» sin que falte sin embargo el comportamiento respectivo (y viceversa). Estos y otros "casos» son muy frecuentes, pero su tener lugar, su razón de ser, se debe a que originariamente rige en la comprensión, en la experiencia, un a priori de correlación entre el comportamiento y el fenómeno.

Denominaremos «polo» a cada uno de estos dos extremos de la correlación a priori; ¿por qué? porque ambos, entre sí, están imantados, se atraen: uno «presta atención» (el comportamiento) y otro «llama la atención» (el fenómeno). Únicamente - e insistimos en esto- porque hay una originaria «atracción» caben distintos casos de «repulsión» (casos nunca desdeñables pero que no deben ser erigidos en lo primordial o lo prioritario). Los dos polos - manteniendo escrupulosamente su mutua irreductibilidad — se requieren, se reclaman, se implican 
entre sí, se coactivan en reciprocidad. Desde luego aunque su estricta y perfecta «co-relación» no sea ni tenga que ser siempre «lograda» la aprioridad de la co-relación indica que los dos polos son inseparables, interdependientes, es decir: la correlación a priori es estrictamente irrompible, indisoluble. Tanto el «realismo» como el «idealismo» - en tanto se sostienen sobre la premisa de una escisión entre un sujeto y un objeto- se alimentan, por su parte, de la tenaz ilusión de separar primero y jerarquizar después uno u otro de los dos polos de la correlación a priori: el realismo pone al objeto en el estatuto de lo independiente e incondicionado, el idealismo hace lo mismo con el sujeto. La única manera de plantarles cara es insistir con firmeza en que olvidan e ignoran la originariedad del a priori de correlación, la imperfecta sincronía entre los dos polos activos en la más mínima o básica expresión de la comprensión ordinaria: un comportamiento y un fenómeno.

¿Cuál es, entonces, la primera conclusión? Que el acto y el proceso de la comprensión — su común y corriente acaecer- incluye y abarca, correlacionados a priori, dos polos tan irreductibles entre sí como inseparables: un comportamiento comprensor y un fenómeno comprendido. $Y$ ¿̨cuál es, sentado esto y respetándolo escrupulosamente, el siguiente paso de la teoría filosófica que estamos esbozando? Indagar en cada uno de los polos por separado: enfocando primero uno y luego el otro. Esta doble tarea - pese a que nos movemos en un nivel de consideración básico y, por así decirlo, «sencillo»— es ardua y complicada. A continuación ofreceremos — con la única pretensión de subrayar una serie de asuntos merecedores de una indagación detallada - unos pocos apuntes de los vericuetos en los que tiene que adentrarse esta segunda fase de la teoría encargada de exponer esta peculiar condición de posibilidad de la comprensión.

Empezaremos con el «fenómeno». Lo consideraremos, aquí, nada más que como uno de los dos polos del a priori de correlación, es decir, como un ingrediente o factor de las condiciones de posibilidad de la ordinaria comprensión. ¿Qué implica esto? Principalmente que lo tematizaremos un instante «antes» de su imprescindible ingreso en un ámbito del saber (sea la comprensión científica o la artística, etc.). Así la desmesurada pregunta a que nos empuja esta vertiente de la investigación es: ¿qué es (un) fenómeno? ¿en qué consiste ser-algo-determinado y, por eso, ser algo comprendido por un comprensor? Avancemos una serie de respuestas tentativas: 
— Un «fenómeno» es algo que destaca, sobresale y resalta; el fenómeno así - y sea cual sea el ámbito en el que comparece- nos interpela, reclama nuestra atención. Pese a que su atraer la atención sobre sí tiene un sesgo «imperativo» y hasta «impositivo» no se trata nunca de un "poder causal». Un fenómeno se distingue y diferencia de lo que ocasionalmente no llama la atención: lo patente remite implícitamente a todo aquello que permanece latente, en lista de espera.

- Cada fenómeno es una "síntesis»: la unidad de una multiplicidad analizable de rasgos (las propiedades y/o relaciones que definen lo en cada caso comprendido y compareciente). La síntesis no es algo que se añada o sobreponga al fenómeno: él es ya su propia síntesis; por esto un fenómeno no es nunca el "resultado» o el «efecto» de una síntesis que se le impone desde otra instancia, ni, por lo tanto, algo "producido", "construido», "constituido». "Fenómeno» es lo que se da y se ofrece al que comprende en el seno de una comprensión regida por la condición de posibilidad a la que aludimos con el término «a priori de correlación» ${ }^{11}$.

- ¿Qué es, pues, lo que se muestra (expone, exhibe, ofrece, brinda)? Se (nos) presenta (ya siempre en tal o cual ámbito del saber) «algo» con unos rasgos, algo con un «sentido». Esos rasgos — los que definen, circunscriben o determinan al «algo» en cuestión - son suyos: esos con los que concretamente comparece; los propios rasgos de algo (gracias a los cuales es tal o es cual) no son necesariamente «innatos» (como afirman las teorías que propugnan para los fenómenos una y sólo una «esencia substancial»): son, en el fondo, "adquiridos», es decir: propios por legítima adquisición, por una apropiación debida (acreditable en el fenómeno mismo).

- En principio algo es sus rasgos — nada más y nada menos- - Sin embargo, a la vez, el algo del que se trata — tal o cual fenómeno- no se identifica absolutamente con los rasgos con los que precisamente se ofrece: nunca algo resulta agotado o saturado íntegra y completamente por los

${ }^{11}$ Queda pendiente indagar en qué consiste la «síntesis». En este punto deberá discutirse una propuesta tradicional: la síntesis está guiada por una esencia o un concepto (de tal manera que comprender algo es necesariamente subsumir un particular bajo un universal, etc). ¿Es esto así o lo que sucede aquí — en la síntesis que es todo fenómeno - es otra cosa bien distinta? ¿no será, tal vez, la síntesis del fenómeno «esquemática»? En el segundo volumen de sus Recherches phénomenologiques Marc Richir encara esta tan difícil como decisiva cuestión. 
rasgos con los que comparece; así en el darse de algo como tal o como cual (siendo esto o siendo aquello) opera un principio de incompletud o un principio de insaturabilidad: un fenómeno, en definitiva, está sostenido y atravesado por un límite intrínseco que — notificando que en todo darse de algo algo también se retrae o sustrae- salvaguarda su riqueza y marca una reserva en el corazón del fenómeno. La «metafísica de la presencia» es, desde esta óptica, la pretensión de saltarse por las bravas este límite intrínseco soñando con una presencia absoluta, íntegra, completa, exhaustiva: la propia, por ejemplo, de un «universo eidético» captado por un «entendimiento intuitivo».

— Un fenómeno está siempre «inscrito» en una «superficie». Dos ejemplos extremos: una galaxia lejanísima es "fenómeno" para nosotros si se registra de algún modo en un radioscopio o un telescopio; por su parte $-\mathrm{y}$ por delirante que sea el propio tema - las "psicofonías» pretenden ser la grabación de voces de los habitantes del más allá: también los espíritus se ve obligados a dejar algún tipo de huella sonora. Se suscita aquí una indagación "gramatológica»: una teoría de la inscripción de los fenómenos (y, a la vez, de las «obras» que constituyen el núcleo palpitante de cada uno de los ámbitos del saber — pues los fenómenos con los que nos topamos comparecen o en obras o desde ellas—) ${ }^{12}$. Una porción de esta teoría se ocuparía de estudiar dos superficies de inscripción: la Sensibilidad y la Lingüisticidad (ambas no son únicamente dos «facultades humanas»: requieren, desde luego, de un ser capaz de pertenecer y participar en el Sentir y en el Decir, pero son algo más: dos formas de acceso a los fenómenos y, a la vez, dos superficies de inscripción de los fenómenos) ${ }^{13}$.

- Los fenómenos son siempre intra-situacionales o intra-mundanos: comparecen «dentro» de una situación, de un mundo.

12 Cada ámbito del saber está organizado en torno a las obras que ocupan su centro (la «familia nuclear» es una obra propia del saber moral moderno, el «parlamento» es una obra peculiar del saber político moderno, el «avión» es una obra específica de la técnica moderna, etc.).

13 Afirmando que los fenómenos —en la comprensión— se registran sensiblemente y/o lingüísticamente (esto es: que la comprensión es tanto lingüística como sensible) no sólo no implica que deba distinguirse entre un «mundo sensible» y otro "mundo inteligible»; esta afirmación, al contrario, permite descartar como absurda e improcedente una separación como la indicada. 
Basten estas rápidas pinceladas para subrayar algunas de las cuestiones que se plantean al indagar sobre uno de los polos del a priori de correlación ${ }^{14}$. Vayamos ahora con el otro polo: el propio del «comportamiento» ${ }^{15}$. ¿Qué es el comportamiento? ¿En qué consiste este peculiar ingrediente de las condiciones de posibilidad de la comprensión?

- En primer lugar, y dicho negativamente: el comportamiento no es la cara o el envoltorio «externo» — un lado «físico» y "público»— de algo más profundo, primordial y recóndito: un «estado mental» (un proceso psíquico «interno» $y$ «privado»); por otra parte el comportamiento tampoco es un «efecto» constreñido y atrapado en el fuego cruzado de dos tipos de causas: una "externa» (un "objeto físico») y otra «interna» (un «estado mental»). Cuando se aborda el comportamiento desde planteamientos así - frecuentes, por cierto, en la filosofía del siglo XX — resulta gravemente deformado y desfigurado.

- Un comportamiento cualquiera es una "operación» llevada a cabo con su término propio: un fenómeno. Las operaciones se caracterizan por estar «regladas»: siguen alguna regla, un modus operandi. Si acudimos al ejemplo de golpear un clavo con un martillo o pilotar un avión esto se ve con facilidad, menos fácil de ver - pero no por ello menos ajustado a la anterior descripción - es el caso del comportamiento «enamorado» o del «comportamiento imaginativo» (cuando tumbado en la cama imagino mis próximas vacaciones): pero todos ellos son operaciones con fenómenos guiadas por reglas inherentes a esos comportamientos tan distintos. Un dolor de espalda — la sensación de dolor, pues - no es un comportamiento, sino un fenómeno intraceptivo que me notifica un daño muscular; el sentimiento de dolor por la pérdida de un ser querido sí es, en cambio, un comportamiento ${ }^{16}$.

${ }^{14}$ Hemos omitido adrede un aspecto central: lo comprendido en cada caso y ocasión del acaecer de la comprensión es un fenómeno en su verdad. Aquí se encuentra, pues, el sitio sistemático de una teoría filosófica de la verdad, la cual debe incluir tanto una definición de la verdad como la elucidación de cuál es su criterio propio.

15 Además del lúcido libro de Maurice Merleau-Ponty, La estructura del comportamiento, ed. Hachette, 1976 (el original es de 1938), es interesante lo que José Luis Pardo expone al respecto en las páginas 115-118 de Sobre los espacios (pintar, escribir, pensar), ed. Serbal, 1991.

16 Ayudan a entender mejor este aspecto de la cuestión libros como El concepto de lo mental, G. Ryle, ed. Paidós, 2005, Estar ahí (cerebro, cuerpo y mundo en la nueva ciencia cognitiva), A. Clark, 
- El comportamiento comprensivo - atento, selectivo- está constantemente enderezado o vertido hacia algo que a la vez, correlativamente, se le ofrece siendo esto o siendo aquello. La reglada operación de cada comportamiento es, por lo tanto, «receptiva»: acoge en cada caso y ocasión «algo determinado», «algo definido». El "poder (de) actuar» —el peculiar «hacer»— del comportamiento implica en el fondo «recibir» un fenómeno; ampliando un interesante hallazgo de Husserl puede afirmarse que la síntesis del fenómeno considerada desde el otro polo es siempre una "síntesis pasiva» ${ }^{17}$. Debe decirse entonces, en definitiva, y en el seno del a priori de correlación, que el comportamiento —en imperfecta simultaneidad con el otro polo- es «reacción», «respuesta», ‘a qué? a algo que interpela, solicita, motiva, llama la atención, o sea: a un fenómeno.

- En el comportamiento algo se revela, se desencubre, se desoculta. Heidegger lo ha destacado en el $\$ 44$ de Ser y tiempo aunque sucumbiendo a la trampa de creer que el "poder de desocultación» es exclusivo y unilateral patrimonio del comportamiento —en vez de ser algo que sucede en y con la propia correlación a priori-; en el tratado de 1927 Heidegger no sólo decía que «en el comportamiento algo se revela», sostenía dando un paso a nuestro juicio erróneo- que «por el comportamiento algo resulta desocultado». Es cierto que su descripción cambió en el escrito "De la esencia de la verdad» ${ }^{18}$ : aquí, con razón, se nos indica que el comportamiento atento está conminado por un imperativo, el de atenerse al fenómeno, dejándolo ser lo que es. Es esta última pista, nos parece, la que merece seguirse.

- Mi comportamiento no es, para mí, prima facie, «fenómeno», pues "fenómeno» es lo en cada ocasión correlativo a mi comportamiento. Sin embargo no es menos cierto — como bien indica el termino "comportarse»el comportamiento incluye una "noticia de sí mismo»: oblicuamente se percata, se advierte. Ilusoriamente se ha pretendido conceder a este peculiar "darse cuenta» un privilegio cognitivo y una prioridad ontológica. Pero lo único seguro es esto: cada uno, cada cual, en sus comportamien-

ed. Paidós, 1999, Fuera de la cabeza, A. Noë, ed. Kairós, 2010. En todos ellos se pretende poner coto al tan extendido «interiorismo mentalista».

17 Un magnífico estudio sobre esta cuestión se encuentra en el libro de Anne Montavont, De la passivité dans la phénoménologie de Husserl, PUF, 1999.

${ }^{18}$ En M. Heidegger, Hitos, ed. Alianza, 2000. 
tos se notifica a sí mismo prendido en una correlación a priori; o sea: comportándonos nos comprendemos a la vez que algo es comprendido (tal o cual «fenómeno» en su acepción primaria).

Hasta aquí nada más que unas notas — susceptibles de precisión y enmienda - sobre cada uno de los dos polos del a priori de correlación. Es el momento de subrayar algo crucial. El a priori de correlación - una de las múltiples condiciones de posibilidad de la comprensión ordinaria- no sólo consta de dos polos: «en medio» de ambos — apuntando a la vez hacia uno y otro- se concreta una «comprensibilidad»; ésta consiste en el común y corriente poder-ser comprendido de algo (un qué) por alguien (un quién). La comprensibilidad, pues, por un lado implica un elenco o surtido de fácticas posibilidades ${ }^{19}$, por otro lado limita con lo incomprensible en la medida en que esas posibilidades son finitas. Tirando de este hilo — cosa que aquí no haremos - se llegaría a otros dos aspectos o vertientes de las condiciones de posibilidad de la comprensión: la circularidad del comprender y su carácter — por decirlo con un término de Gadamerprejuiciado.

Antes dijimos que un comportamiento y un fenómeno no eran sino una artificiosa - aunque provisionalmente necesaria en el arranque de la investigación filosófica- abstracción. ¿Respecto de qué lo son? Indicándolo caeremos en la cuenta de que la correlación a priori que tratamos de explicitar es más compleja de lo que pudiera parecer en principio. Ensartada —embutida, entreveradaen la correlación a priori entre un comportamiento y un fenómeno rige en la comprensión — en la experiencia, en el saber- «otra» correlación a priori entre un «cuerpo» y una «situación» ${ }^{20}$. No se trata, de todos modos, de «dos» correlaciones a priori sino de una sola en la que van ensartados estos cuatro factores. ¿Cómo se llega a esta otra vertiente del a priori de correlación? Siguiendo el hilo de la primera: los comportamientos «remiten» a un cuerpo y los fenómenos (unos patentes y otros latentes) «remiten» a la situación dentro de la cual comparecen. La fórmula provisional que resulta —expuesta en primera persona— es: «yo soy

19 La comprensibilidad estipula las concretas posibilidades de «ingreso», «acceso» $\mathrm{y}$ «encuentro»; un ingreso, acceso y encuentro que concierne a la vez — aunque de modo distinto- a los dos polos del a priori de correlación.

20 «Situación» equivale aquí, aproximadamente, a lo que Heidegger denomina «Umwelt»y Ortega «circunstancia». 
un cuerpo que se comporta respecto a los fenómenos que se me presentan en una situación» ${ }^{21}$. El cuerpo y la situación, en tanto correlacionados a priori, son - como lo eran el comportamiento y el fenómeno- mutuamente irreductibles e inseparables. No son, sin embargo, "polos»: el cuerpo es un centro de irradiación (de comportamientos) y la situación, por su parte, alude a una peculiar «totalidad». Pese a ser indisolubles entre sí se los puede estudiar por separado; ¿qué se puede decir, para empezar, sobre cada uno de ellos?

El «cuerpo» - un «cuerpo»— es eso que soy yo, eso que somos cada uno de nosotros $^{22}$. Yo soy — nada más, nada menos- mi cuerpo, un cuerpo que se comporta, un centro de irradiación de comportamientos, de conductas en las que son alcanzados y revelados fenómenos. Con esta afirmación inicial se intenta desterrar en su raíz un dualismo tan frecuente como inconsistente ${ }^{23}$, ese en el que se dice: «yo soy una mente —o una conciencia— que tiene a su servicio un cuerpo». Desde luego sólo se puede sostener cabalmente que «yo soy mi cuerpo» si se evitan las drásticas simplificaciones y continuas mutilaciones a las que se ha sometido al "cuerpo»: «ser un cuerpo" es algo extraordinariamente complejo $^{24}$. El punto de partida es este: mi cuerpo — eso que yo soy- se comporta (o sea: yo me comporto); los comportamientos a su vez —en tanto operaciones regladas - remiten o requieren aptitudes, competencias. Mi cuerpo es el cuerpo de un ser vivo "inteligente», ¿qué indica primariamente la «inteligencia»? Subraya que yo soy un ser-de-capacidades ${ }^{25}$. Las «capacidades» de un ser vivo

${ }^{21}$ Cada uno de los términos subrayados nombra un ingrediente de las condiciones de posibilidad del acaecer ordinario de la comprensión (sea ésta una comprensión científica, artística, etc.).

${ }^{22}$ Véanse, por ejemplo, François Chirpaz, Le corps, ed. PUF, 1963, Jean-Luc Nancy, Corpus, ed. Arena, 2003, Michela Marzano, La philosophie du corps, ed. PUF, 2007.

${ }^{23}$ Dice con tino John Searle: «Supongo que la mayoría de la gente en nuestra cultura acepta algún tipo de dualismo. Creen tener ambas cosas, una mente y un cuerpo, o un alma y un cuerpo", El redescubrimiento de la mente, ed. Crítica, 1996, p. 125.

${ }^{24}$ Con razón escribe Nancy: «El cuerpo ontológico no está pensado aún», Corpus, op. cit., p. 16.

25 Proponemos distinguir las «capacidades» de las «facultades». Una larga tradición de la psicología y de la filosofía atribuye a los seres humanos —erróneamente a nuestro juicio- la posesión de una serie de «facultades»; una «facultad» es un dispositivo rígido, inflexible, innato, monótono, es decir: una facultad es ya todo lo que es antes de cualquier aprendizaje, éste ni le añade nada ni le quita nada. Ahora bien — y este es el motivo principal por el que consideramos errónea esta atribución — este planteamiento — asociado a teorías sobre la «naturaleza humana»— desfiguran gravemente eso que somos: constriñen indebidamente la permeabilidad del ser humanoun ser «abierto», "versátil», es decir: un ser-de-capacidades, un ser sin «facultades»—.

ÉNDOXA: Series Filosóficas, n. ${ }^{\circ}$ 25, 2010, pp. 235-266. UNED, Madrid 
inteligente son enormemente flexibles, plásticas, y precisamente por eso necesitan ser entrenadas, recibir entrenamiento. Así el cuerpo — ese centro del que emanan comportamientos- se define a través de su «incorporación» en la doble acepción del término: a la vez que, aprendiendo, contrae e incorpora habilidades o destrezas — las cuales afinan y afilan unas capacidades por sí solas romas o imprecisas - se incorpora a los distintos juegos de la comprensión en vigor, vigentes, en marcha. Hay que añadir que el cuerpo que soy es una unidad estratificada —en la que el «cuerpo orgánico» es sólo la «infraestructura»— y muchas otras cosas, pero todas ellas desbordan el marco de lo que aquí resulta oportuno y pertinente.

¿Qué decir, brevemente, de la «situación» con la que mi cuerpo está —en cada ocasión, en cada caso- a priori correlacionado? La situación es una «totalidad» integrada por dos factores: un suelo y un horizonte. El suelo de la situación consiste en una determinada red de posiciones distintas, diferenciadas; cada uno de nosotros ocupa una de esas posiciones, la cual marca y circunscribe un preciso punto de vista, una específica perspectiva; el suelo de la situación, por lo tanto, expresa en el acaecer de la comprensión una intrínseca división, separación, divergencia. El horizonte de la situación, por su parte, pone a las perspectivas «en comunicación» —en «diálogo» en su significado más lato- : favorece su respectiva contaminación y estimula su intersección, es decir: canaliza una convergencia en el seno de la divergencia. Los fenómenos — ya lo hemos señaladocomparecen una y otra vez en la situación, esto es: entre el suelo y el horizonte que la componen. ¿Qué puede añadirse a la noción de "fenómeno» a partir de esta consideración? Principalmente que por brotar y ofrecerse dentro de una situación tensada por un suelo y un horizonte los fenómenos son "poliédricos», "prismáticos», «caleidoscópicos». Antes de introducir un elemento nuevo es importante precisar algo: siendo la situación una totalidad envolvente y ocupando yo una posición podría parecer que yo estoy o que yo soy «dentro» de la situación de experiencia, y sin embargo no es así: «dentro» de la situación lo que se encuentra -entre el suelo y el horizonte- es el «fenómeno». ¿Dónde se ubican entonces el cuerpo y sus comportamientos? En el borde de la situación, en su misma frontera ${ }^{26}$.

${ }^{26}$ Cada uno respecto a los demás (y viceversa) presenta, sin duda, una «faz mundanal» — la del cuerpo y sus comportamientos cuando ambos se tornan «fenómenos»— pero esta no se resuelve nunca en una plena e íntegra «intra-mundanidad».

ÉNDOXA: Series Filosóficas, n. ${ }^{\circ}$ 25, 2010, pp. 235-266. UNED, Madrid 
Si «en medio» de la correlación a priori entre un comportamiento y un fenómeno localizábamos antes una "comprensibilidad» ahora, «en medio» del cuerpo que soy y la situación a la que estoy entregado hallamos una «actividad»: una tarea, un quehacer, una ocupación, una dedicación. Cada «actividad», por su parte, involucra y conjunta la serie de factores o ingredientes que paso a paso hemos ido resaltando. Además —e importa insistir en esto — una «actividad» es la genuina unidad básica o unidad mínima ${ }^{27}$ desde la que se obtienen las relativas abstracciones del cuerpo y la situación y del comportamiento y el fenómeno - atravesados y sostenidos por una correlación a priori-. Y, ¿qué es una o cada «actividad»? Un fragmento más o menos complejo de un ámbito del saber, de un juego de la comprensión, es decir: el acaecer común y corriente de la comprensión (sea ésta científica, artística, etc.) se concreta, en último término, en «actividades» a las que pertenece y en las que participa el existir atareado ${ }^{28}$.

Concluiremos con un esquema y una recapitulación. El esquema es éste:

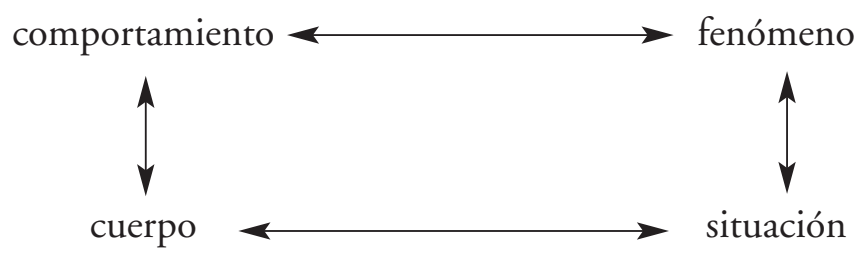

Recapitulando decimos: soy un cuerpo que se comporta en una situación dirigido a fenómenos, todo lo cual ocurre en el seno de actividades — pedazos de un juego de la comprensión, sea éste científico, técnico, moral, político, artístico o religioso. En base al a priori de correlación -que hemos intentado descri-

${ }^{27}$ Heidegger ironizó alguna vez sobre las largas sesiones en el seminario de Husserl en las que los alumnos se esmeraban describiendo con todo detalle la «vivencia de un buzón de correos». Según el planteamiento que estamos formulando la pregunta pertinente al respecto es: ¿¿dentro de qué «actividad» tiene algún sentido — si es que lo tiene- un obsesivo demorarse observando un buzón de correos? La epojé filosófica, en efecto, suspende la «actitud ordinaria», pero lo que gracias a tal suspensión se avoca a describir no son vivencias aisladas, desgajadas de las actividades en las que "ganan un sentido", sino, prima facie, el ordinario y rutinario acaecer de la comprensión considerado según la maraña de las condiciones de posibilidad que lo rigen. Y la unidad básica de ese acaecer es precisamente una «actividad».

${ }^{28}$ Sobre el «existir atareado» véase, por ejemplo, la lección X del curso ¿Qué es filosofía?, José Ortega y Gasset, ed. Alianza, 1998. 
bir respetando su complejidad propia - se legitima la fórmula: las condiciones de posibilidad de la comprensión incluyen y abarcan a la vez al que comprende (un cuerpo comportándose) y a lo comprendido (una trama de fenómenos que comparecen, uno a uno, en una situación).

Antes de terminar vamos a insinuar un último giro en el que despuntan una serie de indagaciones que tendrían que completar lo que acabamos de exponer. A éste giro nos da pie una certera indicación de Jean-Luc Marion: «La intencionalidad, pensada hasta su raíz implica... el In-der-Welt-Sein ${ }^{29}$. La averiguación hasta aquí efectuada conduce en último término hacia el fáctico existir y su radical y originario «ser-en-el-mundo». Decisivo en este punto resulta mostrar y entender que entre el «existir» en su facticidad y el «mundo» no rige ninguna «correlación a priori»; «existir»—en tanto «ex-sistere»— significa sostenerse y mantenerse en el Afuera del mundo, en ese claro abierto y despejado en el que se cruzan los distintos ámbitos del saber que definen y caracterizan una época. La dificultad que debe encararse en este punto puede enunciarse así: ¡cómo el existir fáctico - eso que soy o somos - se mantiene y se sostiene? El existir habita el mundo siendo una coordenada o un límite suyo ${ }^{30}$. Nos topamos aquí, al final, con un enigma que reclama una específica indagación que habrá que emprender en adelante.

\section{2. ¿Es extática la intencionalidad?}

Emprenderemos ahora una breve discusión con dos figuras señeras de la filosofía del siglo XX: Husserl y Heidegger — dos gigantes de los que nunca dejaremos de aprender. El único fin de esta confrontación es aclarar y precisar algunos aspectos de la teoría expuesta en el apartado anterior. Como certeramente ha destacado Michel Henry tanto Husserl como Heidegger - a pesar de las diferencias entre ellos y en medio de ellas - comparten una concepción «extática» de la inten-

29 J-L. Marion, Réduction et donation, PUF, p. 109.

30 El realismo concibe al "existir» — a eso que soy o somos— de modo íntegramente intramundano; el idealismo hace lo contrario: pretende sacar al existir del mundo declarándolo su sujeto, su fundamento extramundano o premundano. Lo que aquí afirmamos es otra cosa — que tendrá que ser debidamente acreditada—: yo no soy ni premundano ni intramundano; el «existir», decimos, es un límite o una coordenada del mundo (además de un cuerpo a priori en correlación con una situación, etc.). 
cionalidad. Si la descripciones que hemos hecho fuesen acertadas resultaría que la «intencionalidad» —eso que preferimos denominar «a priori de correlación»— no es en absoluto «extática» (término que se refiere a un "salir de sí», etc.) ${ }^{31}$. Se nos ha impuesto, por ello, y aunque sólo con el propósito señalado, esbozar una controversia con esos dos maestros. Antes de disputar con uno y con otro - e intentando que la cuestión de dirima bajo la guía y la medida de la «cosa misma»- dibujaremos los perfiles básicos de una concepción «extática» de la intencionalidad.

\subsection{Intencionalidad extática e idealismo filosófico}

La concepción «extática» de la intencionalidad afirma, en primer lugar, que el éxtasis intencional del Yo (sea la "conciencia» en Husserl o la «existencia» en Heidegger) lo avoca a un «salir de sí mismo»; la intencionalidad, por ello, se entiende a partir de la metáfora de un rayo de luz que sale del Yo: partiendo de esta «extraversión» el Yo ilumina algo anteriormente sumido en la oscuridad y la confusión (saliendo de sí, pues, el Yo "pone ante sí» — bajo su foco de luz — todo aquello que comparece y se muestra). Sin embargo la «salida del sí» del Yo no lo es todo, es más: ni siquiera es lo principal o lo primordial (aunque sí, tal vez, lo más llamativo - pues ordinariamente vivimos en el plano que acabamos de describir-). ¿ ¿Por qué? Porque la extraversión del Yo inherente a su «intencionalidad» en el fondo le arrastra a sufrir una terrible «enajenación»; gracias a la intencionalidad, es cierto, el Yo alcanza los fenómenos —iluminándolos con una luz que emana de él一, pero paga al hacerlo un altísimo precio: se pierde a sí mismo en el mundo, atado por las pesadas cadenas de lo mundano. El Yo, pues, esconde en sí mismo el arduo deber y la secreta vocación de recuperarse, de ganarse, de poner remedio a una alienación tan habitual como espantosa. Y ¡cómo puede conseguir remontar esa enajenación producida por el éxtasis intencional? Volviendo sobre sí mismo: sólo así el Yo consigue substraerse al poderoso y pernicioso influjo mundano (tan fuerte que le lleva a creer que la «luz» que alumbra a los fenómenos no es suya, que es, por ejemplo, una luz del propio mundo). El «salir de sí», por lo tanto, está sostenido y aupado desde un originario y radical

31 Miguel García-Baró define así «intencional» e «intencionalidad»: «... habrá que describir su ser como consistiendo muy esencialmente en la versión fuera de sí "hacia» (intentio) el objeto ...", p. 158, Categorias, intencionalidad y números, ed. Tecnos, 1993. 
«volver a sí mismo». El Yo, así, está delimitado por un doble movimiento y vive en su mismo vaivén, en una oscilación entre una y otra: la extraversión (importante, porque gracias a ella los fenómenos resultan «iluminados» y así comparecientes) y la introversión (en la que el Yo expresamente se asume y se reconoce en su auténtico papel de foco de luz).

¿Qué implica, entre otras muchas cosas, la versión «extática» de la intencionalidad? Implica que el Yo está, por un lado, en la correlación a priori con los fenómenos, pero por otro lado, destaca en el Yo el poder extraordinario de separarse y aislarse de esa correlación. Cuando el Yo reconoce y asume ese poder — del que normalmente está «desposeído» por el influjo sobre él de lo que ha iluminado - se erige en el foco primordial, se entiende como la instancia incondicionada, autosuficiente, independiente, que desde sí, por sí y para sí pone y establece la propia "correlación» (esa en la que en un primer momento «se encontró» imbuido, etc.). En el sentido moderno del término es este, netamente, un planteamiento «idealista»; ¿por qué? porque se afirma — con mayor o menor énfasis- que el «Sujeto» (el Yo del que proviene el rayo de luz, según la metáfora empleada) constituye o proyecta desde sí mismo el «mundo», y, así, en definitiva, todo aquello que en él o desde él comparece. El «Sujeto» se revela, entonces, como el único y verdadero «fundamento del mundo».

Para que esta caracterización de la concepción extática de la intencionalidad se ajustara como un guante a Husserl o a Heidegger habría que introducir, sin duda, numerosos matices. Pero no es menos cierto que ambos sostuvieron algo bastante parecido a lo que hemos expuesto ${ }^{32}$. Si esta teoría fuera correcta la intencionalidad sería un «a priori subjetivo» y el Idealismo se erigiría en la única posición filosófica sólida y solvente. Pero es posible dudar de ello. Si el trabajo descriptivo acometido en el primer apartado de este ensayo está bien encaminado —-más allá de que contenga tales o cuales errores parciales - entonces debe decirse que consideradas las cosas a fondo maestros del pensar como Husserl o Heidegger no se atuvieron, al menos en este punto, a los «fenómenos» de la filosofía. Aquí no caben componendas — tampoco «argumentos de autoridad»—: $o$ acertaron ellos $o$ nos equivocamos nosotros.

32 En el caso de Heidegger nos referimos, desde luego, a su primer programa filosófico, el que cristalizó en el tratado Ser y tiempo. 
A nuestro juicio - y esta en nuestra apuesta concreta- Husserl y Heidegger arruinaron su meritorio e impagable hallazgo: no respetaron en su propia irreductibilidad y originariedad el «a priori de correlación» — esa peculiar condición de posibilidad del ordinario acaecer de la comprensión-. Fueron, eso sí, coherentes: en tanto negaban su carácter irreductible orientaron su indagación a intentar derivar la «intencionalidad» de una instancia presuntamente más primordial: la radical y extrema inmanencia del Yo puro en Husserl o la trascendencia del existir en Heidegger. Si preguntamos: ¿Por qué se vieron llevados a «desfigurar» su hallazgo? La respuesta que nos parece más plausible es: porque no consiguieron «deconstruir» suficientemente —manteniéndose firmes en el «fenómeno» que sagazmente localizaron— la poderosa tradición del idealismo moderno; en el fondo la versión "extática» de la intencionalidad confirma y afianza la escisión jerárquica entre el sujeto y el objeto.

Según nuestra descripción — dejamos al juicio de los lectores si es acertada o no- el «a priori de correlación» no esconde ni encierra ninguna clase de «movimiento extático»: ni un «salir de sí» ni un «volver a sí»; el «yo» —eso que soy- está "fuera de sí» en el Afuera del mundo ${ }^{33}$. Cada uno de nosotros nos «descubrimos» - nos comprendemos-en una correlación a priori como uno de sus polos y nos es completamente imposible desgajarnos de ella para a continuación «ponerla» o «establecerla». Además, y prolongando esta tesis, en virtud de la propia correlación a priori de la que estoy prendido, no es cierto que me descubro constituyendo o proyectando el sentido y la verdad de todo aquello que para mí comparece en las situaciones de la comprensión: mis comportamientos —operando según reglas— «reciben» los fenómenos (en lo que a mí respecta la síntesis del fenómeno - la síntesis que es cada fenómeno- es una síntesis "pasiva»).

Los dos planteamientos —el de una intencionalidad radicalmente extática y el de un a priori de correlación ajeno a cualquier suerte de movimiento de extraversión e introversión — han sido expuestos ante un tribunal, quedan así «vistos para sentencia»; juzguen ustedes de qué lado debe inclinarse la balanza.

33 En nuestro artículo «La moderna teoría del conocimiento y el problema del mundo externo», localizable en la revista electrónica «La caverna de Platón» (abril de 2009), exponemos esto con más detalle.

ENDOXA: Series Filosóficas, n. ${ }^{\circ}$ 25, 2010, pp. 235-266. UNED, Madrid 


\subsection{Husserl: intencionalidad e inmanencia de la conciencia}

De la vasta obra de Husserl nos referiremos únicamente a aquellos puntos que más claramente entran en colisión con lo que por nuestra parte tratamos de exponer y defender.

En primer lugar — a diferencia de lo que anteriormente sostuvimos- la epojé auspiciada por Husserl es una epojé reflexiva. Con ella Husserl pretendía llevar a cabo, a la vez, dos operaciones: la desmundanización del Yo y la esencialización de las vivencias de la conciencia. Pero, preguntamos: ¿es posible para un Yo conseguir «desmundanizarse»? ¿es cierto que la filosofía consiste en la obtención de un "conocimiento eidético» (sea sobre las «vivencias» o sobre cualquier otro ente)? Tal vez, se intenta desmundanizar al Yo porque no se ha entendido bien en qué consiste su «mundanidad» y acaso la primera tarea de la filosofía sea explicitar las condiciones de posibilidad de la comprensión ordinaria — algo que poco tiene que ver con el intento de poner de relieve la «esencia» de tales o cuales «hechos».

Husserl define a la fenomenología — una vez consumado su giro idealista en la segunda década del siglo XX - como la ciencia eidética de las vivencias de la conciencia ${ }^{34}$. En este marco se sitúa su tematización de la intencionalidad: se la considera, así, la propiedad esencial de la conciencia (Ideen I, $\$ 84$ ). Es por esto que el idealismo es — sostiene Husserl- la única posición filosófica coherente pues la intencionalidad siendo una propiedad esencial de las vivencias es, en definitiva, una propiedad accidental de sus «objetos». Pero, ¿y si la intencionalidad (o, mejor dicho, el a priori de correlación) no fuese ninguna propiedad de algo y sí una de las múltiples condiciones de posibilidad de la comprensión? ${ }^{35}$.

A la tesis de que la intencionalidad es una propiedad de la conciencia añade Husserl lo siguiente: la conciencia se caracteriza por su «inmanencia» (Ideen I, $\mathbb{S}$ $38, \$ 44, \$ 46)$. Así — acudiendo a los términos «inmanencia» y trascendencia»Husserl recupera la dualidad — presente en una parte importante de la tradición

\footnotetext{
34 Véanse los $\$ 34$ y $\$ 75$ del libro Ideas relativas a una fenomenología pura y una filosofía fenomenológica, ed. FCE (en adelante, Ideen I).

35 Según el a priori de correlación —ese que rige en el acaecer de la comprensión- ésta incluye y abarca tanto al que comprende como a lo comprendido (un cuerpo y una situación, un comportamiento y un fenómeno — más una «actividad» y una comprensibilidad—).
} 
moderna (cartesiana, kantiana, etc.) - entre lo interno temporal y lo externo espacial; por esta razón en el $\$ 42$ de Ideen I escribe: «Una distinción de esencial radicalidad resalta, así, entre el ser como conciencia y el ser como cosa .... En esto se delata justamente la diversidad que hay por principio entre los modos del ser, la más cardinal que hay en general, la que hay entre la conciencia y la realidad en sentido estricto ${ }^{36}$. Si se parte de esta dualidad inevitablemente se concibe a la intencionalidad como un «puente» destinado a "poner en comunicación» dos orillas separadas por un abismo: un puente unilateralmente tendido desde el lado del Yo hasta el lado de los objetos. La asociación entre la "conciencia» y la «inmanencia» implica, además, sostener algo tan extraño y rebuscado como lo siguiente: «yo vivo mis vivencias (internas, temporales, estrictamente privadas) las cuales, a su vez, 'se dirigen' hacia los fenómenos trascendentes (un objeto espacial, etc.) porque en ellas hay una propiedad que lo permite». Pero, ¿̨ivo yo mis vivencias en la «inmanencia» de mi conciencia $o$ llevo a cabo comportamientos en los que opero con fenómenos? En las siempre pulcras y precisas descripciones de Husserl hay siempre a mi juicio- un halo de artificiosidad que lleva a sospechar que aquí algo no cuadra.

Husserl no sólo ubica la intencionalidad — después de concebirla como una propiedad de la conciencia - en la «inmanencia»: la remite, además, a un Yo puro $^{37}$. Éste, por un lado, es el punto fuente del que parte el rayo de luz de la intencionalidad —o, según la metáfora del puente: es la orilla desde la que resulta tendido-; por otro lado, es él mismo más originario que la propia «relación intencional» con los objetos y con el mundo. Con el fin de probar esto último en un sorprendente y muy significativo pasaje de Ideen I (\$ 49) afirma Husserl que el Yo "subsistiría» a una hipotética "aniquilación del mundo» ¿QQué implica esa presunta «subsistencia» del Yo respecto a una teoría de la intencionalidad? Principalmente que el Yo, tomado en su extrema pureza, es capaz de desatarse de la «relación intencional» $y$, por eso mismo, si tal capacidad se acreditara, sería

\footnotetext{
${ }^{36}$ La filosofía, si es un «saber ontológico» (y en base a la diferencia ontológica entes el «ser»y los «entes»), debe abstenerse de pronunciarse sobre diferencias «esenciales» entre entes: su tema — su «fenómeno»— lo constituyen las condiciones de posibilidad de la comprensión (unas condiciones de posibilidad que residen y se asientan en la comprensión del ser).

37 Véase Ideen $I, \$ 80$ y $\$ 31$ de sus Meditaciones cartesianas, ed. FCE.

38 Una lúcida crítica de este pasaje — efectuada desde un planteamiento fenomenológicopuede leerse en el importante artículo de Iso Kern «Los tres caminos de la reducción fenomenológica trascendental en la filosofía de Edmund Husserl», en Agustín Serrano de Haro (ed.), La posibilidad de la fenomenología, ed. Univ. Complutense, 1997.
} 
legítimo sostener que esa «relación» es en su raíz una posición suya, es algo puesto y establecido por él y desde él: la autoposición reflexiva del yo como Sujeto — como fundamento del mundo- sería, entonces, más originaria y primordial que la propia «relación intencional».

Apuntaremos ahora, para ir terminando este rápido repaso de las tesis husserlianas que chocan más frontalmente con lo que hemos intentado sostener, una diferencia más. Husserl cree poder señalar distintas «modalidades» de la intencionalidad $^{39}$. Con esta distinción pretende, ante todo, introducir entre las «vivencias intencionales» una estricta y rígida jerarquía: habrá una y sólo una «modalidad originaria» — la que marca el «ideal de donación» o la «donación ideal»— y unas modalidades derivadas. ¿Cuál es el implícito criterio al que acude aquí Husserl? Al postulado de una absoluta y exhaustiva presencia de algo; por eso la cumbre de la pirámide está constituida por el «entendimiento» (Verstand) que intuye una esencia. Puesto que el conocimiento de los «objetos inmanentes» (las vivencias de la conciencia) es más cierto y seguro que el conocimiento de los «objetos trascendentes» sucede que la ciencia suprema - tanto en dignidad como en certidumbre - es la "Egología»: el saber que el Yo (el Sujeto del mundo) puede alcanzar sobre sí mismo. La vieja ontoteología es sustituida en adelante por la «nueva» - la propia de los «tiempos modernos»— onto-ego-logía. En este punto desemboca el idealismo fenomenológico de Husserl.

Volviendo, para concluir, a la cuestión de la intencionalidad, ¿qué encontramos en Husserl? En primer lugar que la «inmanentiza»: la encierra en esa esfera inmanente denominada "conciencia», es decir, la atrapa en un «interiorismo mentalista». En segundo lugar la analiza como si fuese una "propiedad» — esencial, eso sí- de algo (las «vivencias», los «objetos inmanentes»). Y en tercer lugar la subordina a una instancia que considera más originaria: un Yo puro que, como tal, en su extraordinaria pureza, permanecería incólume aunque el mundo y lo mundano resultasen «aniquilados» ${ }^{40}$. Nada de esto encaja ni es compatible con lo que por nuestra parte hemos descrito en el primer apartado de este artículo.

39 Véase sobre este tema el riguroso libro de Jacques English, Sur l'intentionnalité et ses modes, ed. PUF, 2006. Tal y como lo hemos expuesto el a priori de correlación como tal no se modaliza - es por esto, entre otras cosas, por lo que traemos a colación este tema.

${ }_{40}$ Un brillantísimo ensayo sobre la metafísica del sujeto y el mundo moderno en el que ésta florece se lo debemos a Jean-François Mattéi: La barbarie interior (ensayo sobre el inmundo moderno), ed. Sol, 2005.

ÉNDOXA: Series Filosóficas, . $^{\circ}$ 25, 2010, pp. 235-266. UNED, Madrid 


\subsection{Heidegger: intencionalidad y trascendencia del existir}

Destacaremos, para comenzar, lo que nos parece un enorme acierto de la propuesta de Heidegger: asignar y ubicar la «intencionalidad» no, como hizo Husserl, en unas recónditas "vivencias de la conciencia» sino en los comportamientos: «Los comportamientos tienen la estructura del dirigirse-a, del estar dirigidos-a. Tomando en préstamo un término de la escolástica, la fenomenología designa esta estructura como intencionalidad... puede esclarecerse, inicialmente, el concepto de la intencionalidad de la siguiente forma: todo comportamiento es un comportamiento respecto-de. En sentido estricto, designamos este comportamiento respecto-de cómo el intendere o como la intentio. Todo comportamiento respecto-de y todo estar dirigido-a tiene su específico qué respecto del que se comporta, su qué hacia el que está dirigido. Designamos como intentum este qué, que pertenece a la intentio, respecto del cual es el comportamiento, el qué al que está dirigido. La intencionalidad abarca ambos momentos, la intentio y el intemtum, en su hasta ahora oscura unidad $»^{41}$. No se trata, desde luego, de sustituir una palabra — «vivencia»— por otra — comportamiento» o «conducta»—, lo principal es entender la diferencia entre el planteamiento que arranca de un «yo vivo mis (privadas) vivencias» (adecuadamente captables en una intuición reflexiva en el que se alcanza su esencia) y el que empieza con un «ejerzo comportamientos» (escribo en la pizarra la raíz cuadrada de un número entero, etc.). Por otra parte Husserl creía que había que realizar prolijas y detalladas descripciones del «contenido» de las vivencias ubicadas en la inmanencia: veía en ellas una «forma» y una "materia»" , etc. Pero — si descontamos las reglas que siguen los comportamientos (reglas que puntean su modus operandi) — ¿hay algo que descri-

${ }^{41}$ M. Heidegger, Los problemas fundamentales de la fenomenología, op. cit., p. 87 . En el $₫ 9$ de esta obra se puede consultar la teoría de la intencionalidad que desarrolló Heidegger.

42 A nuestro juicio en la medida en que el hilo conductor de estos análisis del contenido de las vivencias era el «objeto intencional» lo que Husserl hacía era asignar a aquéllas lo que iba encontrando en éste. Nos daba así gato por liebre. En la «deducción metafísica de las categorías», por cierto, Kant hacía algo parecido: primero se topaba con algo perfectamente externo - las clasificaciones de los juicios hechas en los tratados de lógica — y luego por un juego de prestidigitación introducía esa "tabla de los juicios» en la facultad del Sujeto denominada «entendimiento», es decir: situaba "dentro» lo que había hallado antes «fuera» (pero invirtiendo el proceso: lo de dentro es declarado «originario» y lo de fuera «derivado»). El argumento probatorio del idealismo es, así, un perfecto círculo vicioso: «todo lo que se encuentra fuera debe proceder de dentro, y lo pruebo porque lo que está fuera también está dentro (en la interioridad del Sujeto)».

ENDOXA: Series Filosóficas, n. ${ }^{\circ}$ 25, 2010, pp. 235-266. UNED, Madrid 
bir en ellos que sea filosóficamente relevante? Vincenzo Costa y Ramón Rodríguez, respectivamente, nos dicen:

— «Nunca encontramos datos inmanentes, sino manifestaciones de cosas» ${ }^{43}$.

— "Nada hay en el comportamiento que pueda ser descrito sin la pura referencia a, inseparable del objeto referido ${ }^{44}$.

Sin embargo tras este decisivo y crucial hallazgo heideggeriano late una grave omisión: la ausencia de una cabal teoría filosófica del cuerpo; así lo explica Paul Ricoeur:

«Se podrá, entonces, pensar que la filosofía del ser-en-el-mundo de Ser y tiempo ofrece un ámbito más apropiado para una ontología del cuerpo [Leib en alemán, Chair en francés], en virtud de su ruptura con la problemática de la constitución basada en la intencionalidad de la conciencia; ésta es la segunda cara de la paradoja: por razones que habrá que explicar, Ser y tiempo no ha dejado desplegarse una ontología del cuerpo, y es en Husserl, en la obra más claramente dedicada a la renovación del idealismo transcendental, donde se encuentra el esbozo más prometedor de la ontología del cuerpo...» ${ }^{45}(15)$.

Cuando Heidegger acudió, para referirse a nosotros mismos, al extraño término «Dasein» —o «Existenz»— lo hizo con el noble fin de evitar otros nombres tradicionales nada inocentes: alma, mente, conciencia, espíritu, persona, etc. Pero lo que no evitó fue, finalmente, verse avocado a sostener que el Dasein «tie-

\footnotetext{
${ }^{43}$ V. Costa, La generazione della forma (la fenomenologia e il problema della genesi in Husserl e in Derrida), ed. Jaca Book, 1996, p. 91.

44 R. Rodríguez, La transformación hermenéutica de la fenomenología, ed. Tecnos, 1997, p. 68.

45 P. Ricoeur, Sí mismo como otro, ed. S. XXI, 1996, p. 358. A esto añade, en la p. 362: «№ habría que volverse hacia Ser y tiempo para elaborar una ontología del cuerpo que tenga en cuenta igualmente la intimidad con respecto a sí mismo del cuerpo y su apertura al mundo? Ésta es la segunda paradoja evocada anteriormente, a saber, que es Husserl y no Heidegger quien ha abierto el camino a esta ontología, pese al hecho de que el ámbito general de pensamiento de Ser y tiempo parece más apropiado para semejante empresa; al sustituir por la estructura englobadora del seren-el-mundo la problemática de la constitución de un mundo en y por la conciencia, al llamar Dasein, al ente que no pertenece al conjunto de los entes simplemente dados y utilizables, ¿no ha liberado Heidegger, en principio, la problemática del cuerpo propio...?»».
} 
ne un cuerpo ${ }^{46}$ : reiteró, así, finalmente la monótona tesis de la tradicional antropología dualista.

Otro importante acierto del planteamiento de Heidegger —al que ahora solo vamos a aludir- se expone en el importante $\$ 44$ de Ser y tiempo: en los comportamientos del existir se «descubren» (desvelan, revelan) los fenómenos (el martillo se revela al cogerlo y martillar con él, la puerta al abrirla y pasar a la otra habitación, etc.). Pero como dijimos anteriormente aquí fue Heidegger víctima de un tenaz prejuicio idealista que le llevó a sostener algo erróneo: «es por los comportamientos que los entes resultan descubiertos». Prolongando este error ubicó Heidegger las "posibilidades» (nosotros decimos: las posibilidades de la comprensión, las posibilidades en la comprensión) exclusivamente (unilateralmente) del lado de los «existenciarios» del Dasein en vez de situarlas «en medio» del a priori de correlación, de tal manera que conciernen en reciprocidad a sus dos $\operatorname{polos}^{47}$. Félix Duque se pronuncia a favor de esta última tesis cuando escribe: «... la determinación [la fenomenicidad, etc.] surge de una transacción entre mis potencialidades y las posibilidades de las cosas...»" ${ }^{48}$.

El punto clave - y es de lo que trataremos a continuación — se encuentra aquí: Heidegger sostiene que la «intencionalidad» se «fundamenta» en una instancia más

${ }^{46}$ Es cierto lo que afirma Heidegger: «... la intencionalidad .... como estructura esencial del Dasein debe revolucionar todo el concepto de hombre. Sólo entonces se pondrá de manifiesto su importancia filosófica central», Principios metafísicos de la lógica, op. cit., p. 157. Pero esta «revolución» pasa, nos parece, al menos por dos puntos: a) entender que la intencionalidad es algo más que una «estructura esencial» del Dasein (pues lo que más bien sucede es que yo soy un polo del a priori de correlación); b) desarrollar una teoría filosófica del cuerpo, de sus capacidades y sus comportamientos.

47 En el $₫ 9$ de Ser y tiempo distingue Heidegger entre «existenciarios» y «categorías»; los primeros caracterizan a un "quién» y los segundos a un "qué». Esta distinción puede retomarse a la hora de indagar sobre cada uno de los dos polos del a priori de correlación — pero sólo si se cumplen una serie de requisitos ausentes en la propuesta de Heidegger-. ¿Qué requisitos son esos? Por ejemplo los tres siguientes: a) las «posibilidades» abrazan tanto a los existenciarios del comprensor como a las categorías de lo comprendido; b) los existenciarios no son «facultades» sino lo que anteriormente denominamos «capacidades» (en Heidegger la diferenciación de los tres principales existenciarios del Dasein está desgraciadamente influida por la antigua "psicología» de las facultades, esa que distinguía entre entendimiento, voluntad y sentimiento); b) las «categorías» no remiten a una región de lo óntico concebida como un "género supremo» (debe pues discutirse la difícil cuestión de cómo se «divide» la «totalidad de lo óntico»).

48 F. Duque, El mundo por de dentro, ed. Serbal, 1995, p. 32. 
originaria y primordial, en eso que denomina la «trascendencia del Dasein». Entre los muchos textos que podrían citarse mencionaremos el siguiente:

«El problema de la trascendencia no es idéntico con el problema de la intencionalidad. Ésta, en tanto que trascendencia óntica, sólo es posible sobre el fundamento de la trascendencia originaria [del Dasein] ... esta trascendencia originaria hace posible toda relación intencional con el ente» ${ }^{49}$.

Por sostener esto escribió: «La trascendencia y el trascender pertenecen a la índole esencial del ente que, en virtud de la trascendencia como fundamento, existe como intencional, o sea, que existe en el modo de estar confrontado con los demás entes. La intencionalidad es la ratio cognoscendi de la trascendencia [del Dasein]. Ésta es la ratio essendi de la intencionalidad en sus diferentes modos ${ }^{50}$. Heidegger acudió al término "transcendencia» —especialmente en las clases y los artículos inmediatamente posteriores a Ser y tiempo- para nombrar el ser del Dasein. Una consideración superficial de la trascendencia del Dasein ve en ella, nada más, su "salir de sí mismo»; esta superficial orientación es la que conduce - a juicio de Heidegger - a que se confunda la trascendencia del Dasein con la intencionalidad; sin embargo al salir de sí mismo el Dasein sucumbe al poderoso y pernicioso influjo del mundo y lo mundano, o sea: por salir de sí mismo se explica en último término la inautenticidad de la caída. Precisamente por esto cree Heidegger que esto no puede ser todo lo que puede afirmarse sobre la trascendencia del Dasein. El Dasein no sólo se trasciende "saliendo de sí mismo»: más originariamente la trascendencia del Dasein consiste en un «volver a sí mismo»; volviendo a sí mismo el Dasein se des-mundaniza, nihiliza lo óntico, se sustrae a su influjo, etc.; es por esto que los tres comportamientos del Dasein que definen su «autenticidad» son — al menos así lo cree Heidegger - estrictamente auto-referenciales: la angustia, la voz de la conciencia, el resolverse anticipando la propia muerte — cada uno de estos comportamientos marca el punto álgido de los tres principales existenciarios del Dasein, respectivamente el «encontrarse», el «discurso» y la «comprensión» ${ }^{51}$.

${ }^{49}$ M. Heidegger, Principios metafísicos de la lógica, op. cit., p. 159.

50 M. Heidegger, Los problemas fundamentales de la fenomenología, op. cit., pp. 94-95.

51 He expuesto esto con mucho más detalle en el libro El tiempo del sujeto (un diagnóstico de la crisis de la modernidad), ed. Arena, 2010. 
La trascendencia del Dasein, pues, no es sólo su extraversión sino, más originaria y radicalmente, su introversión ${ }^{52}$. El Dasein vive, entonces, oscilando entre dos movimientos: uno centrífugo (que lo arroja en medio del ente y lo intramundaniza) y otro centrípeto (desmundanizándose el Dasein se muestra como el ente «señalado», ese en el que puede buscarse el «sentido del ser en general», etc.).

Si la descripción del a priori de correlación que hicimos en el primer apartado es correcta ni el existir (eso que soy yo o que somos nosotros) sale de sí mismo ni tampoco vuelve a sí mismo. Si describimos el ordinario acaecer de la comprensión según sus condiciones de posibilidad y enfocamos esa porción suya a la que estamos llamando "a priori de correlación» lo que Heidegger sostiene resulta desautorizado. El propio Heidegger — aunque esto no baste desde luego para dirimir el asunto- - a finales de los años treinta le negó al Dasein el «poder de la trascendencia» que antes le había asignado ${ }^{53}$.

Insistiendo en que el Dasein es el ente que se trasciende, etc., Heidegger no sólo pretendía fundamentar la intencionalidad sino que afirmaba a la vez que el Dasein tiene la magnífica facultad de romper por sí mismo el propio «ser-en-elmundo", el Dasein detentaría el enorme poder de quebrantarlo. Pero diciendo esto Heidegger sucumbía, de nuevo, a un profundo prejuicio idealista, ese que le conduce a atribuir al Dasein un papel protagonista: precisamente porque el Dasein es capaz de quebrar la unidad del ser-en-el-mundo se erige en el fundamento del mundo. Por eso sostenía — como colofón a su primer programa filosófico- que tanto el «ser» como el «mundo» no son sino "proyectos del Dasein». Pero en este marco lo único que se puede defender coherentemente no es que el Dasein «es en el mundo» sino que el Dasein «tiene mundo», ¿̨uál? ese que él mismo, por su propio poder, ha proyectado. Pero, ¿no es esto un absurdo, un delirio subjetualista (ese que le llevó a Husserl a creer que el Yo permanecería incólume aunque el mundo entero fuese "aniquilado»)?

52 Respecto a «volver a sí» y con el fin de mostrar en qué se distinguen Husserl y Heidegger cabe decir: en Husserl la vuelta reflexiva alcanza un Yo vacío y permanente, el núcleo inextático de una subjetividad absoluta; en Heidegger, en cambio, el Dasein es «extático» en su misma entraña, por eso nunca cabe para él el puro reposo "cabe sí» (esta es una de las vertientes de la finitud del Dasein).

53 En el segundo apéndice al libro de Ramón Rodríguez Heidegger y la crisis de la época moderna, ed. Síntesis, 2006, he expuesto esta denegación en las pp. 207-208.

ÉNDOXA: Series Filosóficas, n. ${ }^{\circ}$ 25, 2010, pp. 235-266. UNED, Madrid 
Volviendo a la intencionalidad o, como preferimos decir: al a priori de correlación. ¿Qué se le puede «reprochar» a Heidegger? Sobre todo que la subjetivó indebidamente — poniéndola en el exclusivo haber del Dasein-; así en vez de respetarla en su propia irreductibilidad - y con el fin espurio de reforzar y afianzar esa subjetivación- intentó subordinarla a una instancia presuntamente más originaria: la trascendencia del Dasein.

Nos vamos a referir, para poner punto final a estas rápidas anotaciones sobre Heidegger, a dos cuestiones en las que se rozan temas de hondo calado.

En 1928 Heidegger —en un texto que citamos en la nota n. ${ }^{\circ} 45-$ conectaba el asunto de la intencionalidad con la reconsideración de la "pregunta por el hombres ${ }^{54}$. En efecto: mucho se beneficiaría la respuesta a esta pregunta filosófica si se tiene en cuenta el a priori de correlación. Heidegger dio aquí un paso decisivo cuando gracias a su explicitación de la intencionalidad - y discutiendo con Brentano y Husserl- se negó a considerarnos como un "ente psíquico» opuesto a los «entes físicos» ${ }^{55}$. Pero puede darse, si se explica y argumenta bien, un paso más: negar expresamente y con todas sus consecuencias que "yo» en tanto «ser humano» sea un «ente» (por más que, sin duda, presento una faz óntica). Pero, ¿̇si no soy yo (o no somos nosotros) un ente, qué soy entonces? La consideración del a priori de correlación nos lo ha enseñado: yo soy —al menos, en tanto que «me comporto»— un polo de la correlación a priori; soy, pues, ab initio, al menos, un ingrediente o un factor de la condiciones de posibilidad del ordinario acaecer de la comprensión (sea esta comprensión científica, artística, etc.).

Leamos ahora un interesante fragmento de lo que Heidegger exponía en un curso impartido en 1927: «Porque el Dasein, de acuerdo a su propia existencia, es histórico, son variables las posibilidades de acceso a los entes y son diversos los modos de interpretación de estos entes en diferentes momentos históricos» ${ }^{56}$. Dejemos de un lado la tesis de que la razón última de lo que se está sosteniendo es que el «Dasein es histórico». Nos interesa resaltar, principalmente, que las «posibilidades» de la comprensión (la «comprensibilidad» a la que aludimos en

\footnotetext{
${ }^{4}$ Aunque la pregunta central y primordial de la filosofía es la "pregunta por el ser» ésta incluye, como aspecto suyo, la pregunta por quién soy yo o quienes somos nosotros.

55 Véase sobre esto el capítulo II del libro de Ramón Rodríguez La transformación hermenéutica de la fenomenología, ed. Tecnos, 1997.

${ }_{56}$ M. Heidegger, Los problemas fundamentales de la fenomenología, op. cit., p. 48.
} 
el primer apartado) están intrínsecamente sometidas a una originaria «variabilidad»: las posibilidades incluidas en la propia comprensión no son sólo "finitas» sino que son, además, «variables». Es tarea filosófica, desde luego, explicar el por qué y el cómo de esta crucial variabilidad. En esta explicación tendrán que esclarecerse, por ejemplo: la profunda historicidad de la comprensión (y no solo del Dasein que comprende); la inagotable riqueza de lo óntico que alberga y retiene vetas siempre por explorar; cómo la comprensión óntica o el saber fenoménico (en las ciencias, las artes, etc.) remite en última instancia al «ser» y su recurrente «acontecer» (un acontecer del ser — recogido y acogido en una comprensión- que está en la raíz misma de la «variabilidad» de la que estamos tratando). Quedan pendientes, pues, un buen número de jugosas cuestiones.

\section{Conclusión}

Hemos intentado sostener, aunque sólo sea a grandes trazos y dejando muchos temas y problemas por el camino, que el a priori de correlación — asumido según su complejidad propia — nada tiene que ver con la célebre «relación sujeto/objeto»; es más: aquella genuina condición de posibilidad del acto o el proceso de la comprensión revela la forzada artificiosidad de esa escisión y del insoluble "problema» al que da pábulo: la «cuestión» del puente que debe unir esas dos orillas, etc. Así pues ninguno de los dos polos de la correlación a priori que rige la ordinaria comprensión —en su común y corriente acaecer- es adecuadamente descrito cuando se los nombra con esos términos: ni "yo» —el que comprende— es un sujeto ni el "fenómeno" - lo comprendido- es un objeto. Así pues — y gracias a la tematización del a priori de correlación - las tradicionales posiciones filosóficas denominadas «realismo» e «idealismo» pierden el marco común que las sustenta: la operación — con la que se puede soñar, pero que nunca se puede llevar a término- de aislar y separar primero uno u otro de esos polos para, después, erigirlo en lo independiente, lo incondicionado y prioritario en el orden de la fundamentación. Pero la filosofía no «fundamenta» cosa alguna: describe pacientemente la maraña de condiciones de posibilidad que rigen la comprensión. Realismo e idealismo se nutren una y otra vez del vano intento de separar lo inseparable: eso que a priori —en una sincronía imperfecta- está co-relacionado: un comportamiento y un fenómeno, un cuerpo y una situación. Además ocurre lo siguiente: en lo que a mí concierne no estoy entregado al vaivén del salir de mí mismo y el volver a mí mismo, a un doble movimiento centrífugo y 
centrípeto; yo ni salgo hacia el mundo (constituyéndolo, proyectándolo) ni tampoco previamente o más originariamente vuelvo a mí mismo desde el mundo (sustrayéndome a su influjo con tal ímpetu y poder que me reconozco y asumo como una instancia premundana capaz de, desde sí misma, erigirse en el único fundamento del mundo y lo mundano). Este conjunto de descripciones no me son o no nos son en absoluto apropiadas, nos deforman y desfiguran.

Desde luego sacando a la luz esta peculiar e irreductible «estructura» de las condiciones de posibilidad de la comprensión no se resuelven de un plumazo y por arte de magia todas las cuestiones filosóficas, pero sí se consigue ubicar muchas de ellas de tal manera que no se conviertan en puros embrollos o meros galimatías que oscurecen más que aclaran eso que la filosofía, en sus primeros pasos al menos, busca esclarecer. Ojalá que estas páginas hayan contribuido con algo significativo — si quiera sea por la nitidez o profundidad de sus errores- a esta tarea tan noble como difícil.

\section{Bibliografía}

Barbaras, R. (2003). Vie et intentionnalité, París: J. Vrin.

García-BARÓ, M. (1999). Vida y mundo, Madrid: Trotta.

Herrmann, F.-W. von (1981). Der Begriff der Phänomenologie bei Heidegger und Husserl, Frankfurt am Main: V. Klostermann.

HopKINs, B. C. (1998). Intentionality in Husserl and Heidegger, Dordrecht: Kluwer.

Janicaud, D. [ed.] (1995). L' intentionnalité en question, París: J. Vrin.

Paredes Martín, M. ${ }^{a}$ C. (2007). Teorías de la intencionalidad, Madrid: Síntesis

PATOČKA, J. (2004). El movimiento de la existencia humana, Barcelona: Encuentro.

Rodríguez, R. (2004). Del sujeto y la verdad, Madrid: Síntesis.

Ruiz FERnÁndeZ, J. (2008). El sentido de la fenomenología, Madrid: Síntesis.

SCHNell, A. (2004). La genèse de l'apparaître (etudes phénoménologiques sur le statut de l' intentionnalité), París: A. P. F.

Recibido: $16 / 03 / 2010$

Aceptado: 3/06/2010

ENDOXA: Series Filosóficas, n. ${ }^{\circ}$ 25, 2010, pp. 235-266. UNED, Madrid 